BMJ Open

Diabetes

Research

\& Care
To cite: Shibuta T, Waki K, Tomizawa N, et al. Willingness of patients with diabetes to use an ICT-based self-management tool: a cross-sectional study. BMJ Open Diabetes Research and Care 2017;5:e000322. doi:10.1136/bmjdrc-2016000322

Received 9 September 2016 Revised 7 November 2016 Accepted 4 December 2016

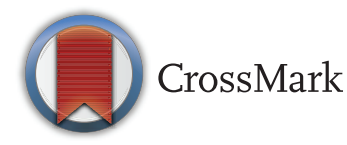

For numbered affiliations see end of article.

Correspondence to Dr Kayo Waki; kwaki-tky@umin.ac.jp

\section{Willingness of patients with diabetes to use an ICT-based self-management tool: a cross-sectional study}

\section{ABSTRACT}

Objectives: To examine the prevalence of the willingness of patients with diabetes to use a selfmanagement tool based on information and communication technology (ICT) such as personal computers, smartphones, and mobile phones; and to examine the patient characteristics associated with that willingness.

Research design and methods: We conducted a cross-sectional interview survey of 312 adults with diabetes at a university hospital in an urban area in Japan. Participants were classified into 2 groups: those who were willing to use an ICT-based self-management tool and those who were unwilling. Multiple logistic regression analysis was used to identify factors associated with the willingness, including clinical and social factors, current use of ICT, self-management practices, self-efficacy, and diabetes-related emotional distress

Results: The mean age of the 312 participants was 66.3 years $(S D=11.5)$ and $198(63 \%)$ were male. Most of the participants $(93 \%)$ had type 2 diabetes. Although only $51(16 \%)$ currently used ICT-based selfmanagement tools, a total of $157(50 \%)$ expressed the willingness to use such a tool. Factors associated with the willingness included: not having nephropathy (OR=2.02, 95\% Cl 1.14 to 3.58); outpatient visits once a month or more (vs less than once a month, $\mathrm{OR}=2.13,95 \% \mathrm{Cl} 1.13$ to 3.99 ); current use of personal computers and/or smartphones (OR=4.91, $95 \% \mathrm{Cl} 2.69$ to 8.98 ); and having greater diabetesrelated emotional distress $(\mathrm{OR}=1.10,95 \% \mathrm{Cl} 1.01$ to 1.20).

Conclusions: Approximately half of the patients showed interest in using an ICT-based selfmanagement tool. Willing patients may expect ICTbased self-management tools to complement outpatient visits and to make self-management easier. Starting with patients who display the willingness factors might optimize programs based on such tools.

\section{INTRODUCTION}

The prevalence of diabetes has been rapidly rising worldwide. ${ }^{1}$ In Japan, that prevalence was estimated as $7.6 \%$ in adults in $2015 .^{1}$

\section{Key messages}

What is already known about this subject?

- Patients with diabetes have difficulty with selfmanagement; adherence to diet and physical activity is low.

- Many information and communication technology-based self-management tools have been developed for patients with diabetes and have improved those patients' glycemic control.

What are the new findings?

- Only $16 \%$ of the study's patients were currently using information and communication technology (ICT)-based self-management tools.

- Approximately half of the patients expressed willingness to use an ICT-based selfmanagement tool.

- The factors significantly associated with that willingness were not having nephropathy, frequent visits to diabetes physicians, current use of personal computers and/or smartphones, and greater diabetes-related emotional distress.

How might these results change the focus of research or clinical practice?

- The findings of this study will help healthcare providers and researchers identify patients willing to use an information and communication technology-based self-management tool more easily, and help in disseminating such tools to those patients efficiently.

Diabetes can lead to a number of complications such as retinopathy, nephropathy, and macrovascular diseases, all of which decrease patient quality of life and increase healthcare expenditures. To prevent and minimize complications, it is important to optimize glycemic control, ${ }^{2} 3$ and the basis of glycemic control is diet and exercise therapy. However, it is difficult for patients to change their lifestyles and maintain desirable behavior and 
good glycemic control. Adherence to diet and physical activity were lower than adherence to medication regimens. ${ }^{4}$ As a result, only $36 \%$ of patients who received inpatient diabetes education could maintain improvement of hemoglobin A1c (HbA1c) levels for 2 years. ${ }^{5}$

With the rapid advance of information and communication technology (ICT), diabetes management is expected to be an area in which the use of the internet and mobile devices could be beneficial. These technologies can overcome time and location barriers through real-time and remote monitoring of data such as blood glucose levels at home, and can facilitate communication between patients and healthcare providers. Many ICT-based self-management tools such as mobile applications have been developed for patients with diabetes ${ }^{6}$ and have improved patients' physical activity levels ${ }^{7}$ and glycemic control. ${ }^{8-12}$

Understanding patients' need for ICT-based selfmanagement tools is essential for disseminating use of them by patients with diabetes-and that need appears to be increasing around the world. For example, in Korea, $71 \%$ of patients with diabetes were interested in using ICT-based healthcare services. ${ }^{13}$ In Japan, however, there have been no reported studies of such needs. Moreover, in Europe, only 14\% of patients with type 2 diabetes who were invited to an intervention study using a Web application actually agreed to the study, the main reason for this non-enrollment being lack of access to the internet. ${ }^{14}$ This fact suggests that we should identify candidates who will be willing to use those tools in advance for efficient and cost-effective diabetes management. The aim of our study was to examine the prevalence of a willingness to use an ICT-based selfmanagement tool among patients with diabetes and the patient characteristics associated with that willingness.

\section{RESEARCH DESIGN AND METHODS}

\section{Study design and participants}

Between August 2014 and March 2015, we made a crosssectional survey consisting of structured interviews and physical measurements of patients at the University of Tokyo Hospital with diabetes who were $\geq 20$ years old. Patients were excluded from the study if they were receiving dialysis treatment, could not communicate in Japanese, were physically/cognitively unable to participate, or if their disease condition was judged as too severe by their physicians.

Participants were recruited by their physicians or through wall posters at the hospital outpatient clinic. The interviewers explained the study to patients who showed interest in the survey and obtained written consent. All of the procedures including structured interviews and physical measurements were conducted by four registered nurses, who had meetings to standardize the method of conducting the interviews; those who had no past experience conducting structured interviews completed a 2-day training session. The data collection procedure took 60-90 min per patient.

\section{Measures \\ Current status and willingness to use ICT-based self-management tools}

In this study, using an ICT-based self-management tool was defined as 'self-management with such ICT devices as personal computers, smartphones, and mobile phones'. We asked the participants whether they were currently using ICT-based self-management tools and whether they were willing to use such tools, giving a show of a smartphone-based self-management application as an example. ${ }^{12}$ Participants responded to the question about willingness on a four-point Likert scale.

Participants unwilling to use an ICT-based selfmanagement tool were asked the reason with a multiplechoice question.

\section{Participants' demographic and clinical characteristics}

In the interviews, participants were asked about working status, family structure, educational level, degree of busyness in daily life, frequency of visits to diabetes physicians and travel time needed for those visits, extent of diabetes education, and current use of ICT (internet, personal computers, and smartphones). Their height, weight, abdominal circumference, and visceral fat area (VFA) were measured. DUALSCAN (HDS-2000; Omron Colin, Tokyo, Japan) was used for measurements of the VFA.

Clinical variables were taken from patients' medical records: diabetes type, time since diagnosis, treatment modality (eg, oral hypoglycemic agent or insulin), related complications, and HbAlc level.

\section{Behavioral and psychological characteristics}

We examined behavioral and psychological factors using four scales. First, the Stages of Change in The Transtheoretical Model ${ }^{15}$ was used to assess participants' status of behavioral changes in diet and exercise. According to the model, participants were categorized into five stages: precontemplation, in which people have no intention to change their behavior; contemplation, in which people are aware that a problem exists and are seriously thinking about overcoming it; preparation, the stage that combines intention and behavior; action, in which individuals have successfully modified their behavior for $<6$ months; and maintenance, in which individuals engage in the new behavior for $\geq 6$ months. We reclassified these five stages into three categories for analysis: precontemplation, contemplation/preparation/ action, and maintenance. We categorized maintenance stage separately because-although action and maintenance stages mean being engaged in desirable behaviorthe goal of diabetes treatment is habituation of selfmanagement practices.

Second, self-management practices were assessed with the Japanese-translated 'Summary of Diabetes Self-Care 
Activities Measure (J-SDSCA)' ${ }^{16}{ }^{17}$ We used 4 subscales with 11 items including specific diet (3 items), exercise (2 items), foot care (5 items), and smoking (1 item). Third, self-efficacy was assessed with the 'Self-Efficacy Scale for Diabetes Self-care', ${ }^{18}$ which was created in Japan and whose reliability and validity were confirmed. Finally, diabetes-related emotional distress was measured with the Japanese version ${ }^{19}$ of the 'Problem Areas in Diabetes Scale'. ${ }^{20}{ }^{21}$ Detailed information on these three scales can be found in the online supplementary material.

\section{Statistical analysis}

Descriptive analyses were used to describe the participants' characteristics. Next, participants were divided into two groups according to their response to the question about willingness: those who were willing to use an ICT-based self-management tool and those who were unwilling. For bivariate analysis, $\chi^{2}$ or Mann-Whitney's U tests were used to examine the differences in characteristics between those two groups. For multiple comparisons after $\chi^{2}$ tests, the Bonferroni method was used.

Multiple logistic regression analysis identified factors related to willingness, adjusted for other variables. Independent variables were selected from those with $\mathrm{p}$ values $<0.2$ on bivariate analysis. Multicollinearity was examined using Spearman's rank correlation coefficient $(\rho)$. After age, diabetes type, and nephropathy were included with the forced entry method, other variables were included with the stepwise procedure in the model. For multiple logistic regression analysis, we divided the scores of diabetes-related emotional distress by four and calculated the OR for every four-point increase because the score difference per item is four points.

We posited that the sample size included at least 10 events per variable based on a previous report. ${ }^{22}$ The sample size was calculated at 267 participants, given that $30 \%$ of the participants were willing to use an ICT-based self-management tool (outcome event) and a maximum of 8 independent variables were included in a multiple logistic regression model based on a similar study in Japan. $^{23}$

The data of some participants were missing for one or two items of self-efficacy or the diabetes-related emotional distress scale. We substituted the participant's mean-item score in each scale for the missing values. The significance level was $\mathrm{p}<0.05$ and SAS Studio 3.4 was used in all analyses.

\section{Ethical considerations}

This study was conducted in compliance with the Declaration of Helsinki and was approved by the Research Ethics Committee of the Graduate School of Medicine, The University of Tokyo (approval number: 10599-(1)). Prior to obtaining written consent, we provided the patients with an explanation of the study purpose and procedures, assured them of the protection of their privacy, and stressed that their participation was voluntary.

\section{RESULTS}

\section{Participants' characteristics}

Of 431 patients asked to participate in this study, 317 agreed to do so, 9 of whom having contacted us after seeing the posters. Four participants did not meet the inclusion criteria and one did not complete the interview. Finally, 312 participants were included in the analyses (response rate: $72 \%$ ).

Participants' characteristics can be found in table 1 . Compared with a nationwide database compiled by the Japan Diabetes Clinical Data Management Study Group in 2013, the participants of this study were older (mean age, 66.3 vs 64.4 years) and had slightly better glycemic control as evidenced by HbAlc $(6.9 \%$ vs $7.0 \%) .{ }^{24}$ Five participants $(2 \%)$ had non-type 1 or non-type 2 diabetes, and were not included in the bivariate analysis of diabetes type and multiple logistic regression analysis. One hundred and ninety-one (61\%) participants currently used personal computers or smartphones in their daily life, not only for diabetes self-management.

\section{Willingness to use an ICT-based self-management tool}

Only $51(16 \%)$ participants currently used ICT-based self-management tools: applications $(39 \%)$, spreadsheet software $(37 \%)$, and pedometer functions in mobile phones (27\%). On the other hand, $157(50 \%)$ participants expressed a willingness to use such a tool in the future: 40 (78\%) of the 51 current users and $117(45 \%)$ of the 261 non-users. One participant did not answer the willingness question and was excluded from the following analyses.

On bivariate analysis, the following variables were associated with willingness to use an ICT-based selfmanagement tool (table 1$)$ : younger age $(p<0.01)$, type 1 diabetes (vs type 2, $\mathrm{p}=0.05$ ), no hypertension $(\mathrm{p}=0.05)$, no nephropathy (stage 1 ) (vs stage 2-4, $\mathrm{p}=0.04)$, employed $(\mathrm{p}<0.01)$, feeling busy in daily life $(p<0.01)$, current use of the internet $(p<0.01)$, personal computers $(p<0.01)$, and smartphones $(p<0.01)$ though not for diabetes self-management, stages of change in diet $(p=0.03)$ and exercise $(p=0.03)$, a higher foot-care score $(\mathrm{p}=0.02)$, and greater diabetes-related emotional distress $(p=0.01)$. As a result of multiple comparisons for stages of change, factors significantly associated with willingness were being in a contemplation/preparation/ action stage in diet (vs precontemplation, $\mathrm{p}=0.02$, after the Bonferroni adjustment) and exercise (vs precontemplation, $\mathrm{p}=0.05$, after the Bonferroni adjustment).

On multiple logistic regression analysis, we integrated the current use of personal computers and smartphones into one variable: current use of personal computers and/or smartphones, because of multicollinearity with each other. The current use of the internet was omitted for the same reason. The factors significantly associated 
Table 1 Participants' characteristics by willingness to use an information and communication technology-based self-management tool ( $\mathrm{n}=312)$

\begin{tabular}{|c|c|c|c|c|}
\hline & All $(n=312)$ & Willing $(n=157)$ & Unwilling ( $n=154)$ & p Value \\
\hline Age (years) & $66.3 \pm 11.5$ & $63.6 \pm 12.3$ & $69.1 \pm 10.1$ & $<0.01$ \\
\hline \multicolumn{5}{|l|}{ Sex } \\
\hline Male & $198(63.5)$ & $102(65.0)$ & $95(61.7)$ & 0.55 \\
\hline \multicolumn{5}{|l|}{ Diabetes type } \\
\hline Type 1 & $16(5.1)$ & $12(7.6)$ & $4(2.6)$ & 0.05 \\
\hline Type 2 & 291 (93.3) & $143(91.1)$ & $147(95.5)$ & \\
\hline Time since diagnosis (years) & $15.3 \pm 10.2$ & $14.3 \pm 9.9$ & $16.3 \pm 10.4$ & 0.09 \\
\hline \multicolumn{5}{|l|}{ Treatment } \\
\hline Oral hypoglycemic agent & $251(80.4)$ & $127(80.9)$ & $123(79.9)$ & 0.82 \\
\hline Insulin & $81(26.0)$ & $46(29.3)$ & $34(22.1)$ & 0.15 \\
\hline Diet only & $33(10.6)$ & $16(10.2)$ & $17(11.0)$ & 0.81 \\
\hline Self-monitoring of blood glucose levels & $103(33.0)$ & $59(37.6)$ & $43(27.9)$ & 0.07 \\
\hline \multicolumn{5}{|l|}{ Complications } \\
\hline Hypertension & $233(74.7)$ & $110(70.1)$ & 123 (79.9) & 0.05 \\
\hline Dyslipidemia & $261(83.7)$ & 129 (82.2) & $132(85.7)$ & 0.39 \\
\hline Nephropathy (stage 2-4) & $97(31.1)$ & $40(25.5)$ & $56(36.4)$ & 0.04 \\
\hline Cerebrovascular disease & $29(9.3)$ & $11(7.0)$ & $18(11.7)$ & 0.16 \\
\hline Cardiovascular disease & $78(25.0)$ & $36(22.9)$ & $42(27.3)$ & 0.38 \\
\hline $\mathrm{HbA1c}(\%)$ & $6.9 \pm 0.9$ & $7.0 \pm 0.9$ & $6.9 \pm 0.8$ & 0.80 \\
\hline Body mass index $\left(\mathrm{kg} / \mathrm{m}^{2}\right)$ & $25.7 \pm 4.7$ & $26.0 \pm 5.1$ & $25.5 \pm 4.3$ & 0.46 \\
\hline Abdominal circumference $(\mathrm{cm})$ & $91.6 \pm 12.2$ & $91.9 \pm 13.3$ & $91.4 \pm 11.1$ & 0.71 \\
\hline Visceral fat area $\left(\mathrm{cm}^{2}\right)$ & $92.2 \pm 49.4$ & $92.7 \pm 49.5$ & $92.1 \pm 49.3$ & 0.76 \\
\hline \multicolumn{5}{|l|}{ Working status } \\
\hline Employed & $151(48.4)$ & $88(56.1)$ & $62(40.3)$ & $<0.01$ \\
\hline \multicolumn{5}{|l|}{ Family } \\
\hline Living alone & $72(23.1)$ & $35(22.3)$ & $37(24.0)$ & 0.72 \\
\hline \multicolumn{5}{|l|}{ Education } \\
\hline University and over & $134(42.9)$ & $75(47.8)$ & $58(37.7)$ & 0.09 \\
\hline \multicolumn{5}{|l|}{ Feeling busy in daily life } \\
\hline Yes & $120(38.5)$ & $73(46.5)$ & $47(30.5)$ & $<0.01$ \\
\hline \multicolumn{5}{|l|}{ Frequency of outpatient visits } \\
\hline Once a month or more & $86(27.6)$ & $51(32.5)$ & $35(22.7)$ & 0.05 \\
\hline Travel time to the hospital (min) & $57.4 \pm 30.7$ & $57.2 \pm 30.6$ & $57.5 \pm 31.0$ & 0.94 \\
\hline \multicolumn{5}{|l|}{ Diabetes education } \\
\hline Hospitalization with education & $124(39.7)$ & $65(41.4)$ & $58(37.7)$ & 0.47 \\
\hline Group education & $139(44.6)$ & $78(49.7)$ & $61(39.6)$ & 0.07 \\
\hline Diet instructions by dietitians & $264(84.6)$ & $134(85.4)$ & $129(83.8)$ & 0.70 \\
\hline \multicolumn{5}{|l|}{ Current use of ICT } \\
\hline Internet & $183(58.7)$ & $119(75.8)$ & $63(40.9)$ & $<0.01$ \\
\hline Personal computers & $171(54.8)$ & $111(70.7)$ & 59 (38.3) & $<0.01$ \\
\hline Smartphones & $105(33.7)$ & $76(48.4)$ & $28(18.2)$ & $<0.01$ \\
\hline \multicolumn{5}{|l|}{ Stages of change (diet) } \\
\hline Precontemplation & $36(11.5)$ & $12(7.6)$ & $24(15.6)$ & $0.03^{*}$ \\
\hline Contemplation & $10(3.2)$ & $4(2.5)$ & $6(3.9)$ & \\
\hline Preparation & $49(15.7)$ & $31(19.7)$ & $18(11.7)$ & \\
\hline Action & $17(5.4)$ & $11(7.0)$ & $6(3.9)$ & \\
\hline Maintenance & $200(64.1)$ & $99(63.1)$ & $100(64.9)$ & \\
\hline \multicolumn{5}{|l|}{ Stages of change (exercise) } \\
\hline Precontemplation & 38 (12.2) & $14(8.9)$ & $24(15.6)$ & $0.03^{*}$ \\
\hline Contemplation & $34(10.9)$ & $23(14.6)$ & $11(7.1)$ & \\
\hline Preparation & $60(19.2)$ & $35(22.3)$ & $25(16.2)$ & \\
\hline Action & $13(4.2)$ & $5(3.2)$ & $7(4.5)$ & \\
\hline Maintenance & $162(51.9)$ & $76(48.4)$ & $86(55.8)$ & \\
\hline \multicolumn{5}{|l|}{ J-SDSCA } \\
\hline Specific diet (range, 0-21) & $13.8 \pm 5.0$ & $13.7 \pm 5.1$ & $13.9 \pm 4.9$ & 0.78 \\
\hline Exercise (range, 0-14) & $6.3 \pm 4.9$ & $6.4 \pm 4.9$ & $6.3 \pm 5.0$ & 0.78 \\
\hline Foot care (range, 0-35) & $18.8 \pm 7.8$ & $19.9 \pm 8.1$ & $17.8 \pm 7.4$ & 0.02 \\
\hline Smoking & $42(13.5)$ & $21(13.4)$ & $21(13.6)$ & 0.95 \\
\hline Self-efficacy (range, 8-32)† & $24.6 \pm 4.3$ & $24.6 \pm 4.2$ & $24.6 \pm 4.4$ & 1.00 \\
\hline Diabetes-related emotional distress (range, $20-100) \ddagger$ & $35.2 \pm 13.4$ & $37.4 \pm 14.8$ & $33.0 \pm 11.5$ & 0.01 \\
\hline
\end{tabular}

Data are shown as mean \pm SD or $n(\%)$. Categorical data were analyzed using the $\chi^{2}$ test, while continuous data were analyzed using Mann-Whitney's U test. Some variables have missing data, which were excluded from calculation of mean and SD and these tests.

${ }^{*}$ Comparison of the three groups: precontemplation, contemplation/preparation/action, maintenance.

†Measured using the Self-Efficacy Scale for Diabetes self-care.

¥Measured using the Japanese version of the Problem Areas in Diabetes Scale.

HbA1c, hemoglobin A1c; ICT, information and communication technology; J-SDSCA, Japanese-translated Summary of Diabetes Self-Care

Activities Measure. 
Table 2 Associated factors of willingness to use an information and communication technology-based self-management tool $(\mathrm{n}=311)$

\begin{tabular}{|c|c|c|c|c|}
\hline \multirow[b]{2}{*}{ Variables } & \multicolumn{2}{|l|}{ Unadjusted } & \multicolumn{2}{|l|}{ Adjusted $(n=278)$} \\
\hline & OR (95\% Cl) & p Value & OR (95\% Cl) & p Value \\
\hline Age & $0.96(0.94$ to 0.98$)$ & $<0.01$ & 0.99 (0.97 to 1.02$)$ & 0.50 \\
\hline \multicolumn{5}{|l|}{ Diabetes type* } \\
\hline Type 1 diabetes & $3.08(0.97$ to 9.79$)$ & 0.06 & $1.61(0.44$ to 5.87$)$ & 0.47 \\
\hline \multicolumn{5}{|l|}{ Nephropathy } \\
\hline No & 1.66 (1.02 to 2.70$)$ & 0.04 & $2.02(1.14$ to 3.58$)$ & 0.02 \\
\hline \multicolumn{5}{|l|}{ Frequency of outpatient visits $†$} \\
\hline Once a month or more & 1.64 (0.99 to 2.71$)$ & 0.06 & 2.13 (1.13 to 3.99$)$ & 0.02 \\
\hline \multicolumn{5}{|c|}{ Current use of personal computers and/or smartphones } \\
\hline Yes & 5.01 (3.04 to 8.25$)$ & $<0.01$ & 4.91 (2.69 to 8.98$)$ & $<0.01$ \\
\hline Diabetes-related emotional distress $\ddagger$ & 1.11 (1.03 to 1.19$)$ & $<0.01$ & $1.10(1.01$ to 1.20$)$ & 0.02 \\
\hline \multicolumn{5}{|c|}{$\begin{array}{l}\text { Final model of the multiple logistic regression analysis: age, diabetes type, and nephropathy were included with the forced entry method; the } \\
\text { others were included with the stepwise method. Participants who had missing data in at least one of the selected variables (those with } p<0.2 \\
\text { on bivariate analysis) were excluded from the multivariate analysis. } \\
\text { *Reference, type } 2 \text { diabetes. } \\
\text { †Reference, less than once a month. } \\
\text { †OR for every four-point increase in the scores measured using the Japanese version of the Problem Areas in Diabetes Scale. }\end{array}$} \\
\hline
\end{tabular}

with willingness were (table 2): no nephropathy $(\mathrm{OR}=2.02,95 \%$ CI 1.14 to $3.58, \mathrm{p}=0.02)$, frequent visits to diabetes physicians (once a month or more vs less than once a month, $\mathrm{OR}=2.13,95 \%$ CI 1.13 to 3.99 , $\mathrm{p}=0.02$ ), current use of personal computers and/or smartphones $(\mathrm{OR}=4.91,95 \%$ CI 2.69 to $8.98, \mathrm{p}<0.01)$, and greater diabetes-related emotional distress $(\mathrm{OR}=1.10,95 \%$ CI 1.01 to $1.20, \mathrm{p}=0.02)$.

Reasons for being unwilling to use an ICT-based selfmanagement tool were: it seemed burdensome $(55 \%)$, current self-management activities were enough $(45 \%)$, it seemed difficult to use $(40 \%)$, it seemed boring in a short period $(10 \%)$, lack of time for using it $(9 \%)$, it seemed ineffective $(8 \%)$, and health condition was too poor to use it $(3 \%)$.

\section{CONCLUSIONS}

This study examined willingness by patients with diabetes to use an ICT-based self-management tool, and the patient characteristics associated with that willingness. Over half of the patients expressed willingness, although only $16 \%$ were currently using any of those tools. Not having nephropathy, frequent visits to diabetes physicians, current use of personal computers and/or smartphones, and greater diabetes-related emotional distress were significantly associated with the willingness. To the best of our knowledge, this is the first study to report potential interest in self-management using ICT among patients with diabetes in Japan.

This study has some limitations. First, it was conducted at a single university hospital in an urban area in Japan. Participants of this study were older and had slightly better glycemic control compared with the national database, ${ }^{24}$ which might make the results of this study less generalizable. Additionally, those who agreed to participate in such a survey may be intrinsically more disposed and thus motivated toward self-management than non-participants. So the sample may be biased and the results should be interpreted with caution. Second, differences in inter-rater variability among interviewers might exist, despite our effort to standardize the interview procedure. Finally, showing the participants a smartphone-based self-management tool might have biased them in favor of willingness to use such a tool; this procedure could give participants an idea of what ICT-based self-management tools are like and could make their response about willingness easier. In future studies, we should also examine the actual use of the tool as with previous studies in other countries. ${ }^{14} 25$

This study indicated that patients who had frequently visited diabetes physicians (once a month or more) and had not had nephropathy were more likely to be willing. As with nephropathy, willing patients were more likely to have fewer comorbidities (eg, hypertension) on bivariate analysis. This might indicate that willing patients tended to need frequent monitoring of blood glucose levels, which resulted in frequent outpatient visits, despite nonexistence of complications. This hypothesis is based on the correlation we found between frequent visits to diabetes physicians and the instruction patients had received in self-monitoring blood glucose levels $(\rho=0.34$, $\mathrm{p}<0.01$; data not shown in the Results section). They might expect that they could utilize ICT-based selfmanagement tools for their blood glucose monitoring at home. At present in Japan, there are no guidelines/regulations for the frequency of outpatient visits of patients with diabetes. It depends on physicians' judgment or patient choice. Although visits to primary care providers every 2 weeks were associated with the fastest achievement of glycemic control, ${ }^{26}$ visiting physicians more frequently is difficult because of the burgeoning number of patients with diabetes and constraints on physicians' time. $^{27}$ ICT-based self-management tools may have an 
effect similar to that of frequent outpatient visits; they could be useful in improving patients' glycemic control and giving them a sense of security through remote monitoring of data measured at home along with interactive communication.

Patients willing to use an ICT-based self-management tool were more likely not to have nephropathy but to have greater diabetes-related emotional distress. There are various aspects of diabetes-related emotional distress such as feeling discouraged about the regimen and difficulty in coping with complications. ${ }^{20}$ In this study, ad hoc analyses showed that patients in the contemplation/preparation/action stage of diet and exercise had greater emotional distress $(p<0.01$; data not shown in the Results section). These results may indicate that diabetes-related emotional distress might be more associated with difficulty in self-management, as shown in a previous study about diet management. ${ }^{28}$ Thus, patients who had diabetes-related emotional distress might be more inclined to be willing to make self-management easier. On the other hand, patients with some complications are likely to have had diabetes for a longer time and may not want to change their lifestyles any more. Further study is needed to understand this mechanism.

Another notable finding was that-after adjustment for other variables, and despite the finding of bivariate analysis -age was not associated with willingness. This showed that the current use of ICT devices such as personal computers and smartphones would be more significantly associated with willingness to use such a tool than was age. This result partly supported a previous study of those with access to the internet that found older patients surprisingly more likely to use an internet-based patient portal—contrary to analysis with all patients. ${ }^{29}$ Several studies indicated that major barriers to using ICT-based self-management tools were inadequate access to the internet and lack of the skills to use it. ${ }^{14}$ Similarly in this study, $40 \%$ of the participants unwilling to use an ICT-based self-management tool gave as a reason that it seemed difficult to use. On the other hand, the oldest user of a smartphone-based selfmanagement application in our previous study ${ }^{12}$ was 77 , and used it easily. In the USA, $\sim 4$ of every 10 elderly people used the internet, and two-thirds of them had looked for health information online. ${ }^{30}$ These facts suggest that we should not automatically exclude elderly patients as potential users of ICT tools; it is important to assess and enhance patients' access to, and skill in using, ICT devices.

To sum up, this is the first study among patients with diabetes in Japan to demonstrate the prevalence of willingness to use an ICT-based self-management tool, and to determine the characteristics of those patients who express that willingness. The need for such a tool should exist among them as it does according to the international trend. Patients with that willingness may expect ICT-based self-management tools to complement outpatient visits and to make self-management easier. Starting with patients who display the willingness factors might optimize programs based on such tools. Future studies should evaluate the patient characteristics associated with the actual use and degree of the effect of the tools in order to provide further tailored support for self-management using ICT.

\section{Author affiliations}

${ }^{1}$ School of Health Sciences and Nursing, Graduate School of Medicine, The University of Tokyo, Tokyo, Japan

${ }^{2}$ Department of Ubiquitous Health Informatics, Graduate School of Medicine, The University of Tokyo, Tokyo, Japan

${ }^{3}$ Department of Diabetes and Metabolic Diseases, Graduate School of

Medicine, The University of Tokyo, Tokyo, Japan

${ }^{4}$ Department of Biomedical Informatics, Graduate School of Medicine, The University of Tokyo, Tokyo, Japan

Acknowledgements This study was financially and materially supported by NTT DOCOMO, Tokyo, Japan. Smartphones used when showing participants an example of ICT-based self-management tools were lent by the corporation.

Contributors TS (the first author) designed the research, collected and analyzed the data, and wrote the manuscript. KW designed the research, interpreted the data, and revised the manuscript. NT collected the data and contributed to the discussion. Al, NY-M, and SY advised about analyses and reviewed the manuscript. HF recruited participants and supervised the research. SK, KF, TY, TK, and KO contributed to the discussion. HW, YI, TS, $\mathrm{MK}$, and RS recruited participants and reviewed the manuscript.

Funding This study was funded by NTT DOCOMO and was partly supported by Japan Society for Promotion of Science KAKENHI grant numbers 26460858 to KW.

Disclaimer Employees of NTT DOCOMO were not involved in any procedures of this study: design, collection or analysis of the data, or writing the manuscript.

Competing interests This study was conducted at the Department of Ubiquitous Health Informatics, which is engaged in a cooperative program between the University of Tokyo and NTT DOCOMO, the funder of the study. KW, NT, SY, HF, SK and KF are members of the department.

Ethics approval Research Ethics Committee of Graduate School of Medicine and Faculty of Medicine, The University of Tokyo.

Provenance and peer review Not commissioned; externally peer reviewed.

Data sharing statement Request for additional unpublished data can be made to the corresponding author and will be evaluated on a case-by-case basis. These data may be available with consent of our study team and proper IRB approval.

Open Access This is an Open Access article distributed in accordance with the Creative Commons Attribution Non Commercial (CC BY-NC 4.0) license, which permits others to distribute, remix, adapt, build upon this work noncommercially, and license their derivative works on different terms, provided the original work is properly cited and the use is non-commercial. See: http:// creativecommons.org/licenses/by-nc/4.0/

\section{REFERENCES}

1. International Diabetes Federation. IDF diabetes Atlas. 7th edn. Brussels, Belgium: International Diabetes Federation, 2015.

2. Stratton IM, Adler AI, Neil HA, et al. Association of glycaemia with macrovascular and microvascular complications of type 2 diabetes (UKPDS 35): prospective observational study. BMJ 2000;321:405-12

3. Ohkubo $\mathrm{Y}$, Kishikawa $\mathrm{H}$, Araki E, et al. Intensive insulin therapy prevents the progression of diabetic microvascular complications in Japanese patients with non-insulin-dependent diabetes mellitus: a randomized prospective 6-year study. Diabetes Res Clin Pract 1995;28:103-17.

4. Coyle ME, Francis K, Chapman Y. Self-management activities in diabetes care: a systematic review. Aust Health Rev 2013;37:513-22. 
5. Akimoto M, Fukunishi I, Kanno K, et al. Psychosocial predictors of relapse among diabetes patients: a 2-year follow-up after inpatient diabetes education. Psychosomatics 2004;45:343-9.

6. Arnhold M, Quade M, Kirch W. Mobile applications for diabetics: a systematic review and expert-based usability evaluation considering the special requirements of diabetes patients age 50 years or older. $J$ Med Internet Res 2014;16:e104.

7. Jennings $\mathrm{CA}$, Vandelanotte $\mathrm{C}$, Caperchione $\mathrm{CM}$, et al. Effectiveness of a web-based physical activity intervention for adults with Type 2 diabetes-a randomised controlled trial. Prev Med 2014;60:33-40.

8. Liang X, Wang Q, Yang X, et al. Effect of mobile phone intervention for diabetes on glycaemic control: a meta-analysis. Diabet Med 2011;28:455-63.

9. Lim S, Kang SM, Shin $\mathrm{H}$, et al. Improved glycemic control without hypoglycemia in elderly diabetic patients using the ubiquitous healthcare service, a new medical information system. Diabetes Care 2011;34:308-13.

10. Ramadas A, Quek KF, Chan CKY, et al. Web-based interventions for the management of type 2 diabetes mellitus: a systematic review of recent evidence. Int J Med Inform 2011;80:389-405.

11. Tang PC, Overhage JM, Chan AS, et al. Online disease management of diabetes: engaging and motivating patients online with enhanced resources-diabetes (EMPOWER-D), a randomized controlled trial. J Am Med Inform Assoc 2013;20:526-34.

12. Waki $\mathrm{K}$, Fujita $\mathrm{H}$, Uchimura $\mathrm{Y}$, et al. DialBetics: a novel smartphone-based self-management support system for type 2 diabetes patients. J Diabetes Sci Technol 2014;8:209-15.

13. Lim S, Kim SY, Kim Jl, et al. A survey on ubiquitous healthcare service demand among diabetic patients. Diabetes Metab $\mathrm{J}$ 2011;35:50-7.

14. Nijland N, van Gemert-Pijnen JEWC, Kelders SM, et al. Factors influencing the use of a Web-based application for supporting the self-care of patients with type 2 diabetes: a longitudinal study. J Med Internet Res 2011;13:e71.

15. Prochaska JO, DiClemente CC, Norcross JC. In search of how people change. Applications to addictive behaviors. Am Psychol 1992;47:1102-14.

16. Daitoku M, Honda I, Okumiya A, et al. Validity and reliability of the Japanese translated "The Summary of Diabetes Self-care Activities Measure". J Jpn Diabetes Soc 2006;49:1-9. Japanese.

17. Toobert DJ, Hampson SE, Glasgow RE. The summary of diabetes self-care activities measure: results from 7 studies and a revised scale. Diabetes Care 2000;23:943-50.
18. Akao A, Koriyama $\mathrm{N}$, Kondo $\mathrm{H}$, et al. Development of self-efficacy scale for diabetes self-care. J Jpn Diabetes Soc 2011;54:128-34. Japanese.

19. Hayashino $\mathrm{Y}$, Okamura $\mathrm{S}$, Matsunaga $\mathrm{S}$, et al. The association between problem areas in diabetes scale scores and glycemic control is modified by types of diabetes therapy: diabetes distress and care registry in Tenri (DDCRT 2). Diabetes Res Clin Pract 2012;97:405-10.

20. Polonsky WH, Anderson BJ, Lohrer PA, et al. Assessment of diabetes-related distress. Diabetes Care 1995;18:754-60.

21. Welch GW, Jacobson AM, Polonsky WH. The problem areas in diabetes scale. An evaluation of its clinical utility. Diabetes Care 1997:20:760-6.

22. Peduzzi P, Concato J, Kemper E, et al. A simulation study of the number of events per variable in logistic regression analysis. $J$ Clin Epidemiol 1996;49:1373-9.

23. Ikeda T, Morita $\mathrm{H}$, Uno $\mathrm{Y}$, et al. Needs and targets for telemedicine -a questionnaire survey of contractants of a home healthcare system in a mountain area. Jpn J Telemed Telecare 2008;4:306-8. Japanese.

24. Japan Diabetes Clinical Data Management Study Group. Basic summary information in 2013. Tokyo: Japan Diabetes Clinical Data Management Study Group, 2014 (cited September 2016). http:// jddm.jp/data/index-2013.html

25. Amante DJ, Hogan TP, Pagoto SL, et al. A systematic review of electronic portal usage among patients with diabetes. Diabetes Technol Ther 2014;16:784-93.

26. Morrison F, Shubina M, Turchin A. Encounter frequency and serum glucose level, blood pressure, and cholesterol level control in patients with diabetes mellitus. Arch Intern Med 2011;171:1542-50.

27. Ostbye T, Yarnall KSH, Krause KM, et al. Is there time for management of patients with chronic diseases in primary care? Ann Fam Med 2005;3:209-14.

28. Franks MM, Hemphill RC, Seidel AJ, et al. Setbacks in diet adherence and emotional distress: a study of older patients with type 2 diabetes and their spouses. Aging Ment Health 2012;16:902-10.

29. Sarkar U, Karter AJ, Liu JY, et al. Social disparities in internet patient portal use in diabetes: evidence that the digital divide extends beyond access. J Am Med Inform Assoc 2011;18:318-21.

30. Zickuhr K. Generations 2010. Washington, DC: Pew Research Center, 2010 (cited September 2016). http://www.pewinternet.org/ 2010/12/16/generations-2010/ 